\title{
Adição de inulina em géis de amido e leite utilizando planejamento experimental de misturas
}

\author{
Addition of inulin to starch and milk gels using an experimental mixture design
}

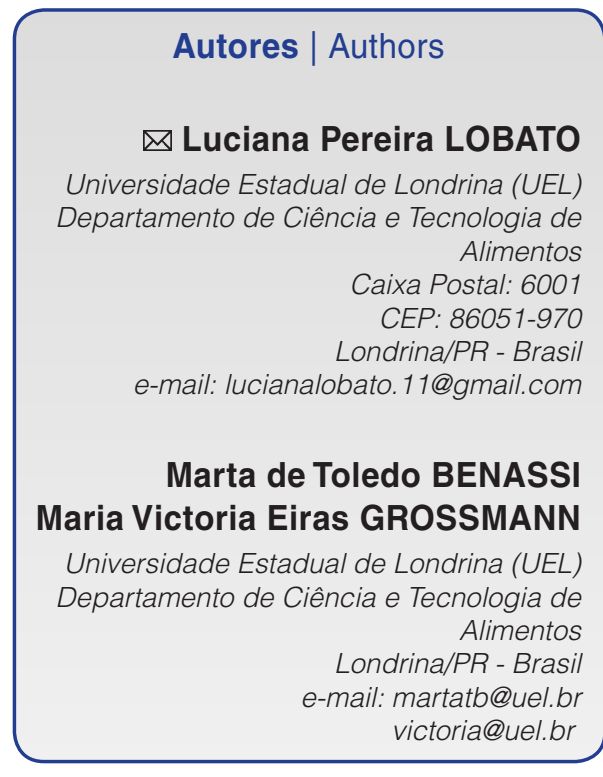

Autor Correspondente / Corresponding Author

Recebido / Received: 18/11/2010 Aprovado / Approved: 12/01/2012 Publicado / Published: jun./2012

\section{Resumo}

O objetivo deste estudo foi investigar o efeito combinado de inulina, amido e leite nas características texturais de géis e de propriedades de pastas empregando o planejamento experimental de misturas. Foram avaliados o perfil viscoamilográfico e a firmeza dos géis. Em todos os parâmetros avaliados, os modelos ajustados mostraram-se influenciados pela presença de inulina, amido e leite, assim como de algumas interações desses ingredientes. A viscosidade máxima e a viscosidade final foram influenciadas positivamente pela concentração de amido e negativamente pelas interações deste com leite e com inulina. A firmeza dos géis aumentou com o aumento do teor de amido, mas a interação amido-inulina foi antagônica, contribuindo para diminuir essa característica. O efeito da interação entre amido e inulina pode ser explicado pelo fato de que a inulina possui maior afinidade pela água, em relação ao amido, ou, ainda, por agir como diluente, fazendo com que haja menor contato entre os grânulos e/ou cadeias de amido. A partir dos resultados encontrados neste estudo, verifica-se que a inclusão da inulina em sistemas amido-leite pode influenciar nas características texturais e de viscosidade, possivelmente refletindo-se nas características sensoriais. Com isso, a avaliação das interações com outros ingredientes da formulação torna-se essencial.

Palavras-chave: Alimentos funcionais; Prebióticos; Fibras; Planejamento experimental de misturas.

\section{Summary}

The objective of this work was to investigate the combined effect of milk, starch and inulin on the textural characteristics of gels and on the pasting properties, using an experimental mixture design. Gel firmness and the amylographic profile were evaluated. For all the parameters evaluated, the fitted models were shown to be influenced by the presence of inulin, starch and milk, as also some of the interactions between the ingredients. The maximum viscosity and final viscosity were positively influenced by the starch concentration and negatively by interactions between the starch and the milk and inulin. Gel firmness increased with increase in starch concentration but the starch / inulin interaction was antagonic, contributing to a decrease in this characteristic. The effect of the starch / inulin interaction could be explained by the higher water affinity of inulin as compared to that of starch, or because it acts as a diluent, decreasing the interaction between the starch granules and/ or chains. From the results found in this study it appears that the inclusion of inulin in milk-starch systems could influence the viscosity and textural characteristics and possibly reflect on the sensory characteristics. Thus, an evaluation of the interactions with the other ingredients of the formulation is essential.

Key words: Functional foods; Prebiotics; Fibres; Experimental mixture design. 


\section{Introdução}

Inulina é um carboidrato de reserva de energia, não digerível, encontrado em vários cereais, frutas e vegetais, como raiz da chicória, cebolas, bananas, trigo e alho (SILVA, 1996; RASCHKA e DANIEL, 2005). Quimicamente, é formada por moléculas de frutose unidas por ligação $\beta(1-2)$, que são tipicamente terminadas por uma molécula de glicose unida por ligação $\alpha(1-2)$ (FLAMM et al., 2001). A fermentação da inulina no cólon aumenta a biomassa bacteriana dentro do ecossistema colônico, o que resulta em benefícios, como o alívio da constipação (IZZO e NINESS, 2001). Pode, ainda, aumentar a absorção de cálcio por alterar $\mathrm{o}$ pH do cólon, em razão da produção de ácidos graxos de cadeia curta (RASCHKA e DANIEL, 2005). Além disso, a inulina aumenta significativamente os níveis de bactérias benéficas - como as bifidobactérias - no trato digestivo, que produzem vitaminas e enzimas que podem contribuir para a eficiência do processo digestivo (IZZO e NINESS, 2001); dessa forma, a inulina é um ingrediente prebiótico (GIBSON e ROBERFROID, 1995).

Há vários estudos em relação à inclusão da inulina em produtos industrializados, como substituto de gordura e açúcar, e agente de textura, entre outros (BRENNAN et al., 2004; EL-NAGAR et al., 2002; SCHALLER-POVOLNY e SMITH, 2001; TUNGLAND e MEYER, 2002). No entanto, há poucos estudos sobre a interação desse ingrediente com outros, como amido e leite. Tárrega e Costell (2006) avaliaram a inclusão da inulina nas propriedades reológicas e sensoriais de sobremesas lácteas com baixo teor de gordura, contendo diferentes concentrações de amido. Esses autores concluíram que a inulina aumentou a doçura e a cremosidade, e que os efeitos da adição de $6 \%$ de inulina no comportamento reológico dessas sobremesas são claramente dependentes da concentração de amido, em função da competição entre inulina e amido pela água.

Zimeri e Kokini (2003a, b) pesquisaram a interação da inulina com amido de milho ceroso, em um sistema aquoso, em termos morfológicos, reológicos e físicoquímicos. Verificaram que as amostras apresentaram duas temperaturas de transição vítrea $(\mathrm{Tg})$ individuais, que correspondem àquelas dos componentes, concluindo que há separação de fase, formando géis fracos. SchallerPovolny e Smith (2002) demonstraram que, na presença de inulina, frações solúveis da proteína do leite tornam-se insolúveis, provavelmente por causa de interações hidrofóbicas. Lobato et al. (2009) investigaram a adição de inulina em géis com amido e leite, e demonstraram que a inclusão desse prebiótico em sobremesas tipo pudins apresenta uma tendência em aumentar a sinérese dos géis, por competição pela água ou pela ação diluente da inulina. Sensorialmente, esses pudins foram bem aceitos pelos provadores e bem discriminados em relação a características texturais, quando aplicada a técnica de análise sensorial de Perfil-Livre.

Planejamentos de misturas devem ser empregados no desenvolvimento de produtos, quando se quer alterar as proporções entre os ingredientes e componentes, tendo em vista que tais proporções são dependentes entre si e que a soma de todas elas deve ser igual a 1 ou 100\% (BARROS NETO et al., 2007). Nwabueze (2010) revisou as aplicações desse tipo de planejamento em produtos lácteos e Cruz et al. (2010) e Granato et al. (2010) o aplicaram no desenvolvimento e na otimização de iogurtes prebióticos e em emulsões, respectivamente.

O objetivo deste trabalho foi avaliar o efeito da interação entre inulina, amido e leite em características de viscosidade e textura de géis, utilizando planejamento experimental de misturas.

\section{Material e métodos}

\subsection{Ingredientes}

O amido de milho, o leite em pó desnatado e o açúcar refinado foram adquiridos no comércio local. A inulina (Raftiline ${ }^{\circledR} \mathrm{GR}$ ) foi doada pela empresa ORAFTI (Bélgica).

\subsection{Análise viscoamilográfica}

As propriedades de pasta das misturas de inulina, amido e leite nas proporções definidas pelo planejamento experimental (Tabela 1) foram estudadas no Viscógrafo Brabender (Brabender, Duisburg-Alemanha), equipado com cabeçote de $700 \mathrm{~cm} . \mathrm{g}$ de sensibilidade, utilizando-se os seguintes parâmetros: temperatura inicial de $30^{\circ} \mathrm{C}$, taxa de aumento e diminuição de temperatura de $1,5^{\circ} \mathrm{C} \cdot \mathrm{min}^{-1}$, temperatura máxima de $95^{\circ} \mathrm{C}$ e temperatura mínima de $50{ }^{\circ} \mathrm{C}$.

\subsection{Preparação dos géis}

Na formulação dos géis, as misturas de sólidos de inulina, amido e leite foram definidas pelo planejamento experimental (Tabela 1), perfazendo um total de 17\% de sólidos. Os teores de água (73\%) e de açúcar (10\%) foram constantes. A porcentagem total de sólidos (27\%, computando o açúcar) utilizada neste estudo foi baseada nos dados de Braga Neto (1999). No entanto, dentre os sólidos, as porcentagens de cada um foram determinadas por testes preliminares.

O leite em pó foi misturado à água $24 \mathrm{~h}$ antes do preparo dos géis (DEPYPERE et al., 2003), para facilitar sua interação com os demais componentes e o restante dos ingredientes (açúcar, amido e inulina) foi adicionado a essa mistura. A seguir, as suspensões foram colocadas no recipiente do Viscógrafo Brabender 
Adição de inulina em géis de amido e leite utilizando planejamento experimental de misturas

LOBATO, L. P. et al.

Tabela 1. Planejamento experimental para estudo das propriedades das misturas de leite em pó, amido e inulina, em proporções reais dos ingredientes na mistura e em pseudocomponentes.

\begin{tabular}{|c|c|c|c|c|c|c|}
\hline \multirow{3}{*}{ Formulação } & \multicolumn{6}{|c|}{ Proporção dos ingredientes na mistura ternária } \\
\hline & \multicolumn{3}{|c|}{ Em concentrações reais } & \multicolumn{3}{|c|}{ Em pseudocomponentes } \\
\hline & Leite $\left(c_{1}\right)$ & Amido $\left(c_{2}\right)$ & Inulina $\left(\mathbf{c}_{3}\right)$ & Leite $\left(X_{1}\right)$ & Amido $\left(X_{2}\right)$ & Inulina $\left(\mathbf{X}_{3}\right)$ \\
\hline 1 & 0,70 & 0,26 & 0,04 & 0,958 & 0 & 0,042 \\
\hline 2 & 0,47 & 0,35 & 0,18 & 0 & 0,375 & 0,625 \\
\hline 3 & 0,70 & 0,27 & 0,03 & 0,958 & 0,042 & 0 \\
\hline 4 & 0,62 & 0,35 & 0,03 & 0,625 & 0,375 & 0 \\
\hline 5 & 0,51 & 0,26 & 0,23 & 0,167 & 0 & 0,833 \\
\hline 6 & 0,47 & 0,30 & 0,23 & 0 & 0,167 & 0,833 \\
\hline 7 & 0,578 & 0,298 & 0,123 & 0,451 & 0,160 & 0,389 \\
\hline 8 & 0,578 & 0,298 & 0,123 & 0,451 & 0,160 & 0,389 \\
\hline 9 & 0,578 & 0,298 & 0,123 & 0,451 & 0,160 & 0,389 \\
\hline
\end{tabular}

$c_{1}+c_{2}+c_{3}=1$ ou $100 \%$

(Brabender, Alemanha), aquecidas $\left(3^{\circ} \mathrm{C} \cdot \mathrm{min}^{-1}\right)$ até $95{ }^{\circ} \mathrm{C}$ e permaneceram nessa temperatura por $3 \mathrm{~min}$. As pastas quentes foram despejadas em recipientes plásticos, tampados com filme de polietileno, resfriadas à temperatura ambiente e, posteriormente, armazenadas a $4^{\circ} \mathrm{C}$, por $24 \mathrm{~h}$.

\subsection{Análise de textura}

Para a análise de textura, foi utilizado o Texturômetro TA-XT2i (STABLE MICRO SYSTEMS, 2001), sendo o registro feito por meio do Software XTRAD. O parâmetro avaliado foi a firmeza ou a dureza $(N)$, definida fisicamente como força necessária para produzir uma deformação e, instrumentalmente, como pico de força durante o primeiro ciclo de compressão, obtido a partir de curvas de força versus tempo e área dos gráficos. As condições padronizadas para o teste foram: carga de 0,05 N, ponta da prova cilíndrica de acrílico $\left(P_{0,5}\right)$, com $15 \mathrm{~mm}$ de diâmetro e $30 \mathrm{~mm}$ de comprimento, com profundidade de penetração de $5 \mathrm{~mm}$ e velocidade de penetração de 2,0 mm. $\mathrm{s}^{-1}$. Os testes foram realizados em duplicata.

\subsection{Planejamento experimental e análise estatística}

Foi aplicado um delineamento simplex-centroide para misturas de três componentes expandido com pontos centrais e limites superiores e inferiores, de acordo com o software Statistica 7.1 (STATSOFT, 2006). Os limites para cada ingrediente foram estabelecidos a partir de ensaios prévios (47-70\% para leite; $26-35 \%$ para amido; $3-23 \%$ para inulina). As proporções em cada formulação, expressas em concentrações reais e em pseudocomponentes (BARROS NETO et al., 2007), estão apresentadas na Tabela 1. O experimento consistiu de sete diferentes formulações com duas replicações no ponto central. Após a coleta de dados, o modelo canônico de Scheffé para três componentes (Equação 1) foi usado para modelar as respostas.

$$
\mathrm{Y}=\beta_{1} \mathrm{X}_{1}+\beta_{2} \mathrm{X}_{2}+\beta_{3} \mathrm{X}_{3}+\beta_{12} \mathrm{X}_{1} \mathrm{X}_{2}+\beta_{13} \mathrm{X}_{1} \mathrm{X}_{3}+\beta_{23} \mathrm{X}_{2} \mathrm{X}_{3}
$$

onde: $Y$ = variável dependente; $\beta$ ' = parâmetro estimado para cada componente linear para a predição do modelo; $\beta_{\mathrm{ii}=}$ coeficiente para interação binária; $X_{1}=$ leite; $X_{2}=$ amido; $X_{3}=$ inulina.

As variáveis dependentes avaliadas foram: viscosidade máxima no aquecimento, viscosidade final e firmeza dos géis.

Os modelos matemáticos ajustados a cada resposta foram submetidos à análise de variância (ANOVA) para avaliar a significância $(p<0,05)$ e o coeficiente ajustado de determinação ( $R^{2}$ ajustado). Para a análise dos dados e a construção de gráficos, também foi utilizado o software Statistica (StatSoft Inc., Tulsa, USA) versão 7.1.

\section{Resultados e discussão}

\subsection{Análise viscoamilográfica}

Este estudo permitiu avaliar o efeito da inulina e do leite nas fases de gelatinização e retrogradação do amido. De acordo com a análise de variância, os modelos ajustados para viscosidade máxima no aquecimento e viscosidade final explicaram 100 e 98\% da variação, respectivamente (Tabela 2 ). Esses parâmetros foram influenciados positivamente pelos teores de inulina, amido e leite, e negativamente pela interação entre amido e inulina. A viscosidade máxima no aquecimento também foi influenciada negativamente pela interação entre leite e amido.

Analisando-se a Figura 1, pode-se observar que há um aumento da viscosidade máxima no aquecimento e da viscosidade final quando se aumenta a concentração de amido. Segundo Abu-Jdayil et al. (2004), o aumento 
Adição de inulina em géis de amido e leite utilizando planejamento experimental de misturas

LOBATO, L. P. et al.

Tabela 2. Coeficientes de regressão e análise de variância dos modelos ajustados à viscosidade máxima no aquecimento, à viscosidade final das pastas e à firmeza (propriedade de textura) contendo misturas de amido, leite e inulina.

\begin{tabular}{cccc} 
Coeficientes $^{1}$ & $\begin{array}{c}\text { Viscosidade máxima } \\
\text { no aquecimento }\end{array}$ & $\begin{array}{c}\text { Viscosidade final } \\
\left(\mathbf{a ~ 5 0}{ }^{\circ} \mathbf{C}\right)\end{array}$ & $\begin{array}{c}\text { Firmeza } \\
\text { dos géis }\end{array}$ \\
$\beta_{1}$ & $311,29^{*}$ & $433,51^{*}$ & $0,44^{*}$ \\
$\beta_{2}$ & $2317,71^{*}$ & $3788,48^{*}$ & $2,43^{*}$ \\
$\beta_{3}$ & $135,47^{*}$ & $186,84^{*}$ & $0,09^{*}$ \\
$\beta_{12}$ & $-1636,79^{*}$ & $-3382,59$ & - \\
$\beta_{13}$ & 36,75 & - & - \\
$\beta_{23}$ & $-1936,72^{*}$ & $-3705,19^{*}$ & $-0,97^{*}$ \\
Significância do modelo $(\mathbf{p})$ & $<0,003$ & 0,012 & $<0,001$ \\
$\mathbf{R}^{2}$ ajustado & 1,00 & 0,98 & 0,99 \\
\hline
\end{tabular}

${ }^{1} Y=\beta_{1} X_{1}+\beta_{2} X_{2}+\beta_{3} X_{3}+\beta_{12} X_{1} X_{2}+\beta_{13} X_{1} X_{3}+\beta_{23} X_{2} ; X_{1}=$ leite; $X_{2}$ amido de milho; $X_{3}=$ inulina; ${ }^{*}$ coeficientes significativos.
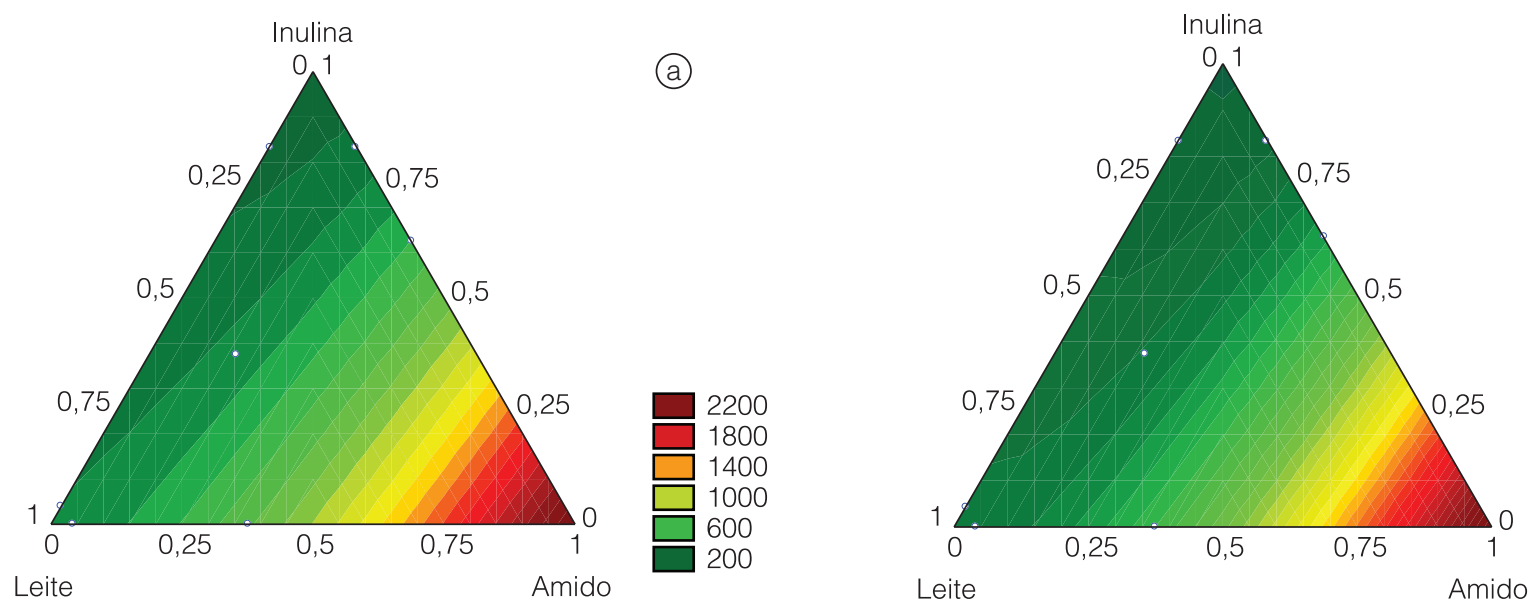

(b)

Figura 1. Superfícies de resposta obtidas pelo modelo experimental (em termos de pseudocomponentes) para (a) viscosidade máxima no aquecimento e (b) viscosidade final. Área entre pontos delimita a região analisada experimentalmente.

da concentração de amido causa um grande aumento na consistência da pasta, pois há maior quantidade de grânulos presentes no sistema.

Os coeficientes apresentados na Tabela 2 também evidenciam a influência da interação do leite com o amido na viscosidade máxima no aquecimento. A inclusão de outros ingredientes a suspensões de amido tem seu efeito dependente da concentração deste, pois, em baixas quantidades, a viscosidade diminui simplesmente pelo efeito diluente dos outros componentes (GOEL et al., 1999). Matser e Steeneken (1997) relatam que a viscosidade do amido é maior na presença de leite, quando as proteínas do leite serão excluídas dos grânulos de amido inchados, se concentrando entre eles e colaborando para o aumento da viscosidade. Tal fato pode ser atribuído à maior resistência dos grânulos de amido quando em sistemas amido-leite (TÁRREGA e COSTELL, 2006). No entanto, no presente estudo foi verificada uma interação negativa entre amido e leite.

A interação negativa entre amido e inulina (Tabela 2) está de acordo com Tárrega e Costell (2006), que verificaram que a adição de inulina ao leite desnatado, para amostras com $4 \%$ de amido, resultou em menores valores de viscosidade aparente, pois, com parte da água ligada nas cadeias de inulina, o inchamento dos grânulos de amido foi limitado, o volume de partículas inchadas foi menor e a viscosidade do sistema diminuiu. Embora a concentração de 4\% de amido possa parecer pequena, considerando-se que o sistema continha também proteínas do leite, lactose e inulina, é possível que a competição pela água tenha diminuído a capacidade de intumescimento do amido. No entanto, esses autores também demonstraram que, para amostras contendo 2,5 e 3,25\% de amido na suspensão total, a adição de inulina ao leite desnatado não modificou o perfil de viscosidade. Nessas amostras com menores concentrações de amido, havia água suficiente no sistema, de tal maneira que a adição de inulina não influenciou no processo de inchamento do grânulo de amido.

De acordo com Bishay (1998), a diminuição de viscosidade de suspensões de amido na presença de inulina pode ocorrer por causa da maior afinidade da inulina pela água, ou seja, mais água se liga à menor e 
mais móvel cadeia. Nesse caso, parte da água se liga às cadeias de inulina, o inchamento dos grânulos fica limitado, o volume de partículas inchadas diminui e a viscosidade do sistema se torna menor.

Zimeri e Kokini (2003b) estudaram as propriedades reológicas de sistemas água-inulina-amido, com diferentes razões dos sólidos. Esses pesquisadores concluíram que a inulina não interage sinergicamente com o amido. No entanto, há uma influência indireta de um ingrediente sobre o outro, pois a inulina pode agir como diluente.

De acordo com Schaller-Povolny e Smith (2001), a similaridade de respostas entre géis com gordura e aqueles com leite desnatado adicionados de inulina pode ser em razão da habilidade desta em ligar moléculas de água e de uma possível interação entre algumas proteínas do leite e a inulina. Essa interação pode aumentar o peso molecular da fração de proteínas do leite, aumentando a viscosidade da fase contínua. Todavia, não foi verificada interação significativa neste estudo.

Deve-se levar em consideração que as diferenças nas propriedades das pastas podem ser atribuídas, também, à presença de proteínas do soro e outros componentes do leite, e também à sacarose (10\%) adicionada. Apesar disso, os diferentes efeitos da inulina, nas diferentes concentrações desta e dos outros componentes, podem ser atribuídos tanto à sua ação diluente como à sua afinidade pela água.

\subsection{Firmeza dos géis}

O modelo ajustado para firmeza, segundo a análise de variância, explicou 99\% da variação (Tabela 2). A firmeza dos géis foi influenciada positivamente pelos teores de inulina, amido e leite, e pela interação negativa entre amido e inulina. De acordo com os coeficientes dessas variáveis, o efeito do amido foi 5,5 vezes maior do que o do leite e 27 vezes maior que o da inulina. Gonzalez-Tomás et al. (2008) também verificaram que parâmetros viscoelásticos de sistemas contendo leite, inulina (2,5; 5,0 e 7,5\%) e amido (3,25 ou 4,0\%) são mais influenciados pela concentração deste último do que pelos diferentes teores ou tipos de inulina.

Na Figura 2, está apresentada a superfície de resposta obtida do modelo experimental ajustado aos resultados de firmeza. Verifica-se que a firmeza dos géis aumenta com o aumento dos teores de amido. Relações entre inulina e firmeza foram descritas por Brennan et al. (2004). Avaliando-se o efeito de sua adição nas propriedades texturais de macarrão, os autores encontraram que há uma tendência de diminuição da dureza quando aumenta a concentração. Então, a diminuição da disponibilidade de água e, consequentemente, do índice de inchamento dos

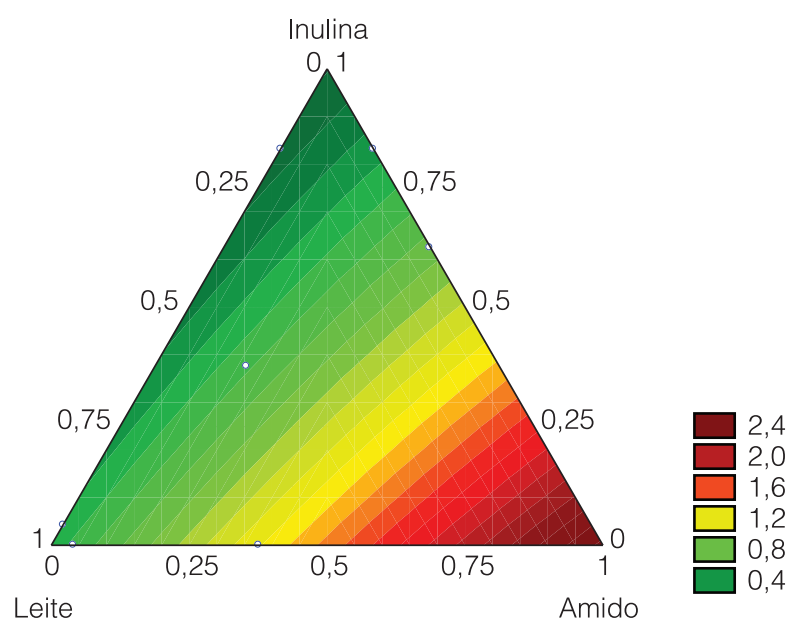

Figura 2. Superfície de resposta gerada pelo modelo experimental (em termos de pseudocomponentes) da propriedade de textura dos géis: firmeza (dureza). Área entre pontos delimita a região analisada experimentalmente.

grânulos, em razão da presença de inulina, podem estar associados com uma menor gelatinização, um menor contato entre partículas e uma menor força necessária para penetrar no gel. De acordo com os autores, tal fato pode se refletir na redução da digestibilidade, assim como, também, do índice glicêmico.

Os géis com maiores porcentagens de amido foram aqueles com maiores valores para firmeza. Segundo Brennan et al. (2004), a firmeza pode estar relacionada com a hidratação dos grânulos de amido durante o processo de cozimento e sua consequente gelatinização. A maior quantidade de grânulos de amido em dispersão, havendo disponibilidade de água suficiente, faz com que haja maior inchamento e maior contato entre as partículas, refletindo-se em maior força necessária para romper a estrutura formada na gelatinização.

A menor força necessária para deformar o gel encontrou-se naquelas formulações com maiores quantidades de inulina. Analisando-se a Tabela 2, verifica-se que há uma interação negativa entre amido e inulina, o que pode ser verificado também na Figura 2, que indica que o aumento do teor de inulina na suspensão de amido demonstra uma diminuição na firmeza.

Esse ingrediente possui grande afinidade pela água, podendo reduzir a disponibilidade desta para gelatinização do amido (BRENNAN et al., 2004). Ainda, segundo Zimeri e Kokini (2003a), em suspensões cuja concentração total de polímeros seja menor que 20\%, a inulina ainda pode estar agindo como diluente, fazendo com que haja menor contato entre os grânulos.

\section{Conclusões}

O efeito combinado de inulina, amido e leite foi avaliado, sendo, principalmente, observado que há uma 
Adição de inulina em géis de amido e leite utilizando planejamento experimental de misturas

LOBATO, L. P. et al.

incompatibilidade entre amido e inulina se misturados em altas concentrações por causa da competição pela água disponível no sistema pelos ingredientes em estudo. Sendo a inulina uma fibra solúvel e, dessa forma, um composto prebiótico com propriedades fisiológicas importantes para a saúde humana, sua inclusão em alimentos processados tem se tornado importante por facilitar o acesso da população a esse composto, assim como se torna relevante a avaliação da sua interação com outros ingredientes. Conclui-se que inulina apresenta grande afinidade pelas moléculas de água, podendo alterar a disponibilidade desta para outros componentes do produto, como o amido e proteínas, modificando a firmeza e a viscosidade, entre outros fatores texturais e sensoriais. Além disso, a ferramenta estatística de planejamento experimental de misturas mostrou-se excelente para esse tipo de investigação de interação de ingredientes.

\section{Referências}

ABU-JDAYIL, B.; MOHAMEED, H.; EASSA, A. Rheology of wheat starch-milk-sugar systems: effect of starch concentration, sugar type and concentration, and milk fat content. Journal of Food Engineering, Oxford, v. 64, n. 2, p. 207-212, 2004. http://dx.doi. org/10.1016/j.jfoodeng.2003.09.034

BARROS NETO, B.; SCARMINIO, I. S.; BRUNS, R. E. Como Fazer Experimentos. 3. ed. Campinas: Editora Unicamp, 2007. 480 p.

BISHAY, I. E. Rheological characterization of inulin. In: WILLIAMS P. A.; PHILLIPS G. O. (Eds.). Gums and Stabilizers for the Food Industry. Cambridge: Royal Society of Chemistry, 1998. p. 201-210.

BRAGA NETO, J. A. Desenvolvimento de Produto Alimentar: uma Sistematização Interativa Pela Aplicação Combinada de Métodos para o Planejamento, Modelagem, Análise e Otimização de Pudim. 1999. 146 f. Tese (Doutorado em Ciência de Alimentos)-Universidade Estadual de Londrina, Londrina, 1999.

BRENNAN, C. S.; KURI, V.; TUDORICA, C. M. Inulin-enriched pasta: effects on textural properties and starch degradation. Food Chemistry, Oxford, v. 86, n. 2, p. 189-193, 2004. http:// dx.doi.org/10.1016/j.foodchem.2003.08.034

CRUZ, A. G.; FARIA, J. A. F.; WALTER, E. H. M.; ANDRADE, R. R.; CAVALCANTE, R. N.; GRANATO, D.; OlIVEIRA, C. A. F. Processing optimization of probiotic yogurt containing glucose oxidase using response surface methodology. Journal of Dairy Science, Champaign, v. 93, n. 11, p. 5069-5081, 2010. http:// dx.doi.org/10.3168/jds.2010-3336

DEPYPERE, F.; VERBEKEN, D.; THAS, O.; DEWETTINCK, K. Mixture design approach on the dynamic rheological and uniaxial compression behaviour of milk desserts. Food Hydrocolloids,
Oxford, v. 17, n. 3, p. 311-320, 2003. http://dx.doi.org/10.1016/ S0268-005X(02)00092-9

EL-NAGAR, G.; CLOWES, G.; TUDORICA, C. M.; KURI, V.; BRENNAN, C. S. Rheological quality and stability of yog-ice cream with added inulin. International Journal of Dairy Technology, Oxford, v. 55, p. 89-93, 2002. http://dx.doi. org/10.1046/j.1471-0307.2002.00042.x

FLAMM, G.; GLINSMANN, W.; KRITCHEVSKY, D.; PROSKY, L.; ROBERFROID, M. Inulin and Oligofructose as Dietary Fiber: A Review of the Evidence. Critical Reviews in Food Science and Nutrition, United Kingdom, v. 41, n. 5, p. 353-362, 2001.http:// dx.doi.org/10.1080/20014091091841

GIBSON, G. R.; ROBERFROID, M. B. Dietary modulation of the human colonic microbiota: introducing the concept of prebiotics. Journal of Nutrition, Bethesda, v. 125, n. 6, p. 1401-1412, 1995.

GOEL, P. K.; SINGHAL, R. S.; KULKARNI, P. R. Studies on interactions of corn starch with casein and casein hydrolysates. Food Chemistry, Oxford, v. 64, n. 3, p. 383-389, 1999. http:// dx.doi.org/10.1016/S0308-8146(98)00134-4

GONZALEZ-TOMÁS, L.; COLL-MARQUÉS, J.; COSTELL, E. Viscoelasticity of inulin-starch-based dairy systems. Influence of inulin average chain length. Food Hidrocolloyds, Oxford, v. 22, n. 7, p. 1372-1380, 2008. http://dx.doi.org/10.1016/j. foodhyd.2007.08.001

GRANATO, D.; CASTRO, I. A.; ELLENDERSEN, L. S. N.; MASSON, M. L. Physical stability assessment and sensory optimization of a dairy-free emulsion using response surface methodology. Journal of Food Science, Oxford, v. 75, n. 3, p. S149-S155, 2010. http://dx.doi.org/10.1111/j.1750-3841.2010.01514.x

IZZO, M.; NINESS, K. Formulating nutrition bars with inulin and oligofructose. Cereal Foods World, Saint Paul, v. 46, n. 3, p. 102-106, 2001.

LOBATO, L. P.; GROSSMANN, M. V. E.; BENASSI, M. T. Inulin addition in starch-based dairy desserts: Instrumental texture and sensory aspects. Food Science and Technology International, Espanha, v. 15, n. 4, p. 317-323, 2009. http:// dx.doi.org/10.1177/1082013209341331

MATSER, A. M.; STEENEKEN, P. A. M. Rheological properties of highly cross-linked waxy maize starch in aqueous suspensions of skim milk components. Effects of the concentration of starch and skim milk components. Carbohydrate Polymers, Oxford, v. 32, n. 1-3, p. 297-305, 1997. http://dx.doi.org/10.1016/S01448617(96)00162-2

NWABUEZE, T. U. Review article: Basic steps in adapting response surface methodology as mathematical modelling for bioprocess optimisation in the food systems. International Journal of Food Science and Technology, Oxford, v. 45, n. 9, p. 1768-1776, 2010. http://dx.doi.org/10.1111/j.13652621.2010.02256.x 
Adição de inulina em géis de amido e leite utilizando planejamento experimental de misturas

LOBATO, L. P. et al.

RASCHKA, L.; DANIEL, H. Mechanisms underlying the effects of inulin-type fructans on calcium absorption in the large intestine of rats. Bone, v. 37, p. 728-735, 2005.

SCHALLER-POVOLNY, L. A.; SMITH, D. E. Viscosity and freezing point of a reduced fat ice cream mix as related to inulin content. Milchwissenschaft - Milk Science International, v. 56, p. 25-29, 2001.

SCHALLER-POVOLNY, L. A.; SMITH, D. E. Interaction of milk proteins with inulin. Milchwissenschaft - Milk Science International, v. 57, n. 9-10, p. 494-497, 2002.

SILVA, R. F. Use of inulin as a natural texture modifier. Cereal Foods World, v. 41, n.10, p. 792-794, 1996.

STABLE MICROSYSTEMS. Product Manual of Texture Analyser TA-XT2i. 2001. Disponível em: <www.stablemicrosystems.com>. STATSOFT. STATISTICA for Windows. version 7.1. Tulsa: StatSoft Inc., 2006. Software.
TÁRREGA, A.; COSTELL, E. Effect of inulin addition on rheological and sensory properties of fat-free starch-based dairy desserts. International Dairy Journal, Oxford, v. 16, n. 9, p. 1104-1112, 2006. http://dx.doi.org/10.1016/j.idairyj.2005.09.002

TUNGLAND, B. C.; MEYER, D. Nondigestible Oligo- and Polysaccharides (Dietary Fiber): Their physiology and role in human health and food. Comprehensive Reviews in food Science and food safety, Malden, v. 1, n. 3, p. 73-77, 2002. http://dx.doi.org/10.1111/j.1541-4337.2002.tb00009.x

ZIMERI J. E.; KOKINI, J. L. Phase transitions of inulin-waxy maize starch systems in limited moisture environments. Carbohydrate Polymers, Oxford, v. 51, n. 2, p. 183-190, 2003a. http://dx.doi. org/10.1016/S0144-8617(02)00127-3

ZIMERI, J. E.; KOKINI J. L. Rheological properties of inulinwaxy maize starch systems. Carbohydrate Polymers, Oxford, v. 52, n. 1, p. 67-85, 2003b. http://dx.doi.org/10.1016/S01448617(02)00268-0 